\title{
Pulmonary alveolar hemorrhage from a pulmonary artery false aneurysm after Swan-Ganz catheterization in a thoracic aortic aneurysm patient
}

-a case report-

\author{
Daisuke Sugiyama ${ }^{1,4}$, Shigeo Ikeno ${ }^{1}$, Tetsuya Tsuchihashi ${ }^{1}$, Shigeru Yokota ${ }^{1}$, Hiroaki Ina ${ }^{1}$, \\ Tetsuya Kono ${ }^{2}$, Kunihiko Yamashita ${ }^{3}$, and Mikito Kawamata ${ }^{4}$ \\ Departments of ${ }^{1}$ Anesthesia, ${ }^{2}$ Cardiovascular Surgery, ${ }^{3}$ Radiology, Japanese Red Cross Society of Suwa Hospital, Suwa, \\ ${ }^{4}$ Department of Anesthesiology and Resuscitology, Shinshu University School of Medicine, Matsumoto, Japan
}

Pulmonary artery (PA) rupture caused by a PA Swan-Ganz catheter is a rare complication but remains fatal in almost $50 \%$ of cases. False aneurysm of the PA is a rare presentation of PA rupture and should be considered as a possible diagnosis in a patient with a new lung mass after PA catheterization. We present a case of sudden-onset pulmonary alveolar hemorrhage during cardiovascular surgery due to a traumatic PA false aneurysm. The Swan-Ganz catheter might have been displaced by the thoracic aortic aneurysm with displacement of the catheter causing the false aneurysm and bleeding. (Korean J Anesthesiol 2014; 67: 346-349)

Key Words: False aneurysm, Pulmonary artery, Swan-Ganz catheterization.

Pulmonary artery (PA) rupture, a rare complication of flowdirected PA Swan-Ganz catheterization, is estimated to occur at a frequency of 0.05 to $0.2 \%$ [1-3]. The mortality rate associated with this severe complication is estimated to be $40-50 \%$ [4]. Death is usually due to massive hemoptysis [2]. False aneurysm of the PA is a rare presentation of PA rupture and should be considered as a possible diagnosis in a patient with a new lung mass after PA catheterization [5]. Here, we present a case of suddenonset pulmonary alveolar hemorrhage during cardiovascular surgery, due to a traumatic PA false aneurysm. The Swan-Ganz catheter might have been displaced by the thoracic aortic aneurysm with displacement of the catheter causing the false aneurysm and bleeding.

\section{Case Report}

A 77-year-old woman, $156 \mathrm{~cm}$ in height and weighing $55 \mathrm{~kg}$, was diagnosed as having angina pectoris and aneurysm of the thoracic aorta, and she was scheduled to undergo coronary artery bypass grafting and aortic arch replacement. She had been

Received: April 25, 2013. Revised: 1st, July 8, 2013; 2nd, July 10, 2013. Accepted: July 12, 2013.

Corresponding author: Daisuke Sugiyama, M.D., Department of Anesthesia, Japanese Red Cross Society of Suwa Hospital, 5-11-50, Kogandori, Suwa 392-8510, Japan. Tel: 81-266526111, Fax: 81-266576036, E-mail: sugidai@shinshu-u.ac.jp

(c) This is an open-access article distributed under the terms of the Creative Commons Attribution Non-Commercial License (http:// creativecommons.org/licenses/by-nc/3.0/), which permits unrestricted non-commercial use, distribution, and reproduction in any medium, provided the original work is properly cited. 
a smoker for more than 50 years and had also been diagnosed as having chronic obstructive pulmonary disease (COPD) complicated by PA hypertension. The patient was receiving treatment with oral diltiazem hydrochloride (100 $\mathrm{mg} /$ day) and furosemide (20 mg/day), and mean preoperative PA pressure was 20-30 $\mathrm{mmHg}$. Preoperative laboratory tests revealed no coagulation abnormalities or any other notable abnormalities. At surgery, anesthesia was induced with propofol (80 mg), fentanyl (200 $\mu \mathrm{g})$ and muscle relaxation with rocuronium $(40 \mathrm{mg})$, and tracheal intubation was performed using a normal endotracheal tube (7 mm in internal diameter; Parker Flex-Tip ${ }^{\mathrm{TM}}$, Parker Medical, USA). No marked circulatory variations or abnormalities were observed during the induction of the general anesthesia. Anesthesia was maintained with $40 \%$ of oxygen, propofol (target-controlled infusion: $2.0 \mu \mathrm{g} / \mathrm{ml})$, and remifentanil $(0.2 \mu \mathrm{g} / \mathrm{kg} / \mathrm{min})$. A central venous catheter and a PA Swan-Ganz catheter were placed via the right internal jugular vein prior to the start of the surgery. The PA Swan-Ganz catheter was advanced up to the PA while the pressure waveforms were checked under the guidance of transesophageal echocardiography, and it was fixed at $40 \mathrm{~cm}$ after $1 \mathrm{~cm}$ was pulled out confirming wedging of the catheter tip in the PA. PA pressure after Swan-Ganz catheter insertion was
$22 \mathrm{mmHg}$ (mean), and pulmonary capillary wedge pressure was $18 \mathrm{mmHg}$.

Maximum airway pressure suddenly increased to $26 \mathrm{cmH}_{2} \mathrm{O}$ from $15 \mathrm{cmH}_{2} \mathrm{O} 30$ minutes after the beginning of surgery, when the internal carotid artery graft was being secured for the coronary artery bypass. Endotracheal hemorrhage was detected, and the tracheal tube became filled and occluded with blood. There had been no change in wedge waveform of the PA Swan-Ganz catheter before the bleeding occurred. Ventilation was disrupted for 3 minutes with a transient fall of $\mathrm{SpO}_{2}$ to $86 \%$. However, positive pressure ventilation was maintained at airway pressures as high as 20 to $30 \mathrm{cmH}_{2} \mathrm{O}$ with positive end-expiratory pressure (PEEP: $6 \mathrm{cmH}_{2} \mathrm{O}$ ) while suction of the blood filling the tracheal tube was performed, and the bleeding ceased 15 minutes after it had been detected. Bronchoscopic observation revealed numerous clots in the tracheal tube, with complete occlusion of the right main bronchus. A total of $300 \mathrm{ml}$ of blood was aspirated from the airway. As continuation of the surgery was deemed impossible, the surgery was suspended and the patient was admitted to the intensive care unit (ICU) with the tracheal tube in place.

A postoperative chest X-ray showed decreased lucency of the
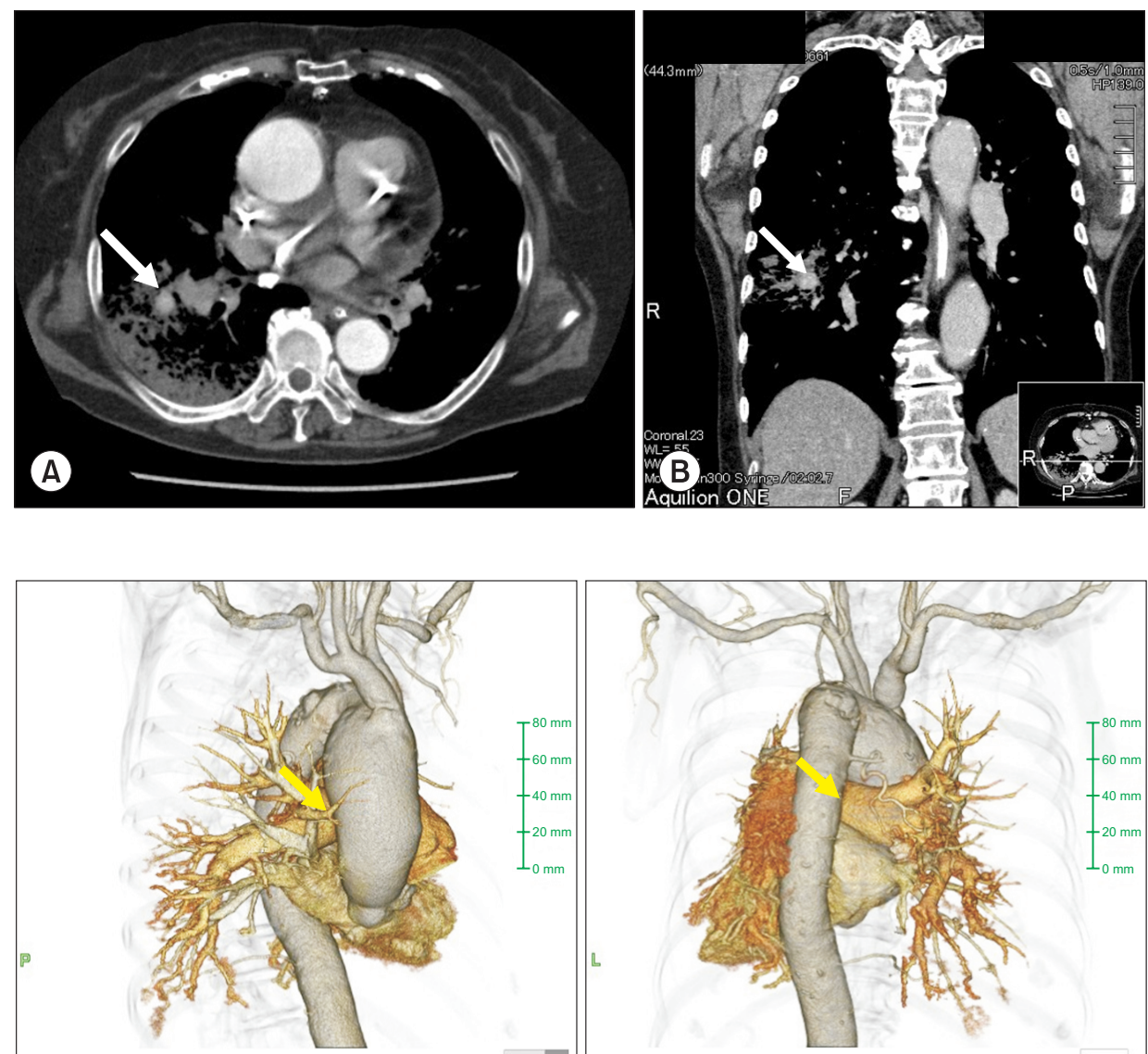

(A)

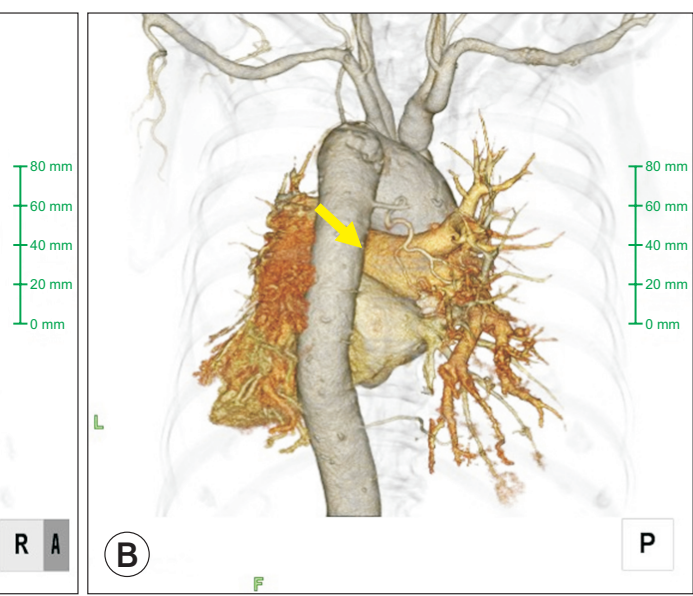

Fig. 1. Chest CT just after surgery in the transverse section (A) and coronal section (B). CT revealed a contrastenhanced false aneurysm measuring 2 $\mathrm{cm}$ in diameter in the right PA. Arrow indicates a contrast-enhanced false aneurysm.

Fig. 2. Reconstructive 3D visualization from the presurgical CT scan: (A) anteroposterior view, and (B) posteroanterior view. The right main pulmonary artery was pressed by the thoracic artery aneurysm (arrow). 


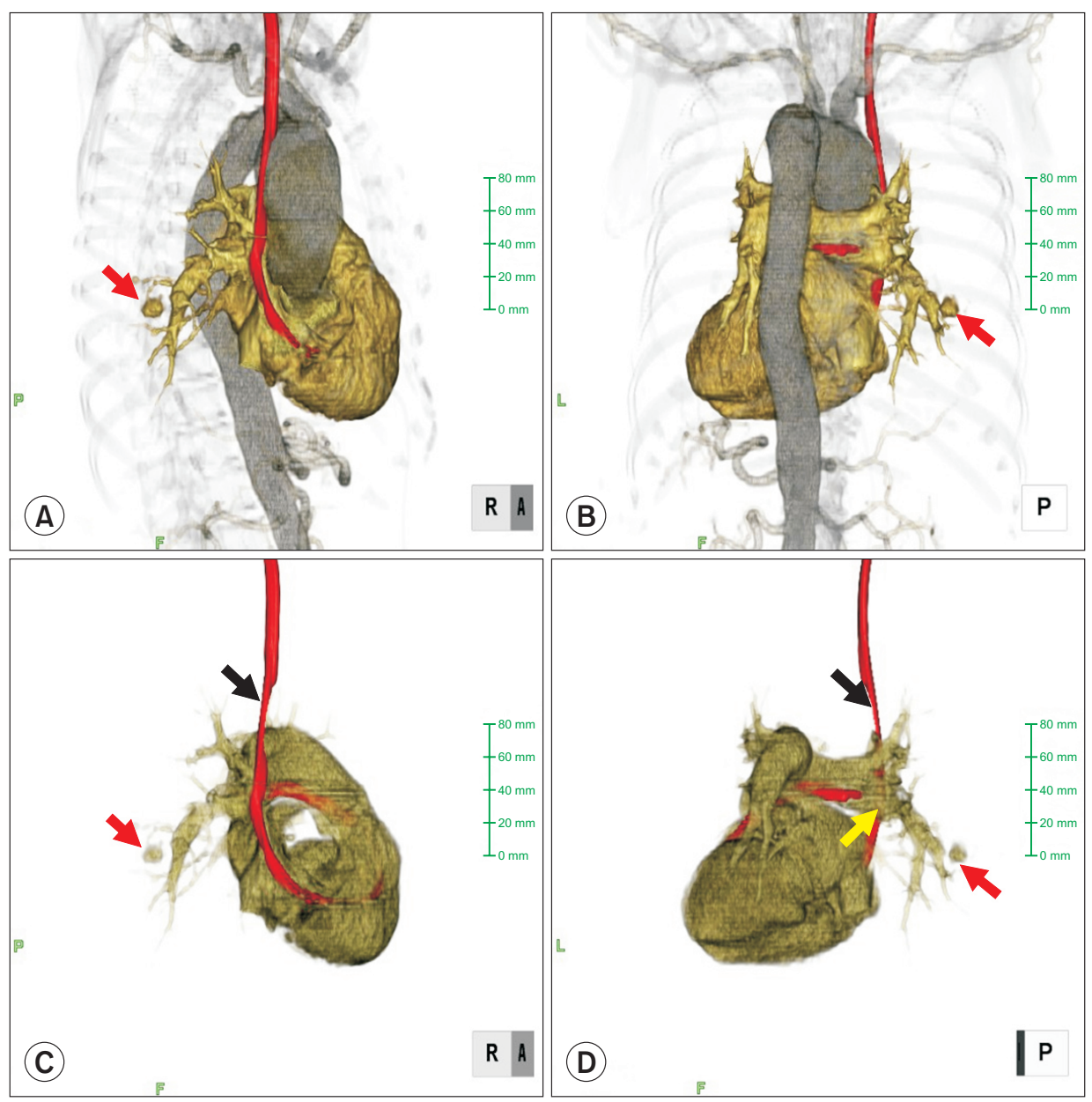

Fig. 3. Reconstructive 3D visualization from the postsurgical CT scan: (A) anteroposterior view, (B) posteroanterior view, (C) anteroposterior view without the aorta, and (D) posteroanterior view without the aorta. The PA Swan-Ganz catheter had shifted at the thoracic artery aneurysm level (black arrow). The tip of the PA Swan-Ganz catheter was maintained at a distance from the PA aneurysm (red and yellow arrows). right lower lung field. Chest CT revealed a contrast-enhanced false aneurysm measuring $2 \mathrm{~cm}$ in diameter in the right PA (Fig. 1). Conservative treatment by mechanical ventilation with applied PEEP $\left(6-8 \mathrm{cmH}_{2} \mathrm{O}\right)$ was selected over invasive treatment because the false aneurysm was small in size and bleeding from the aneurysm had ceased. Retrospectively, chest 3D CT images were confirmed (Fig. 2). The right main PA was pressed by the thoracic aortic aneurysm. A chest $3 \mathrm{D}$ CT after surgery revealed that the PA Swan-Ganz catheter had shifted at the thoracic artery aneurysm level (Fig. 3). The tip of the PA Swan-Ganz catheter was maintained at a distance from PA aneurysm (Fig. 3). A repeat chest X-ray and CT on the 16th postoperative day revealed improvement, and the contrast-enhanced false PA aneurysm could no longer be visualized. The patient's respiratory condition also improved, and she was extubated and discharged from the ICU on the 20th postoperative day.

\section{Discussion}

A PA Swan-Ganz catheter is usually implanted via the right internal jugular vein. Since a PA Swan-Ganz catheter introduced via the right internal jugular vein is likely to be placed in the right $\mathrm{PA}$, iatrogenic trauma caused by the placement of this catheter involves the middle and inferior lobar branches of the right PA in approximately $90 \%$ of cases [3], as in the present case. The risk factors for PA injury caused by PA catheterization include advanced age, pulmonary hypertension, anticoagulant therapy, hypothermia, faulty placement of the catheter, and faulty operation of the balloon [3]. Of these, advanced age and pulmonary hypertension associated with COPD were the relevant risk factors in our patient. The balloon was operated very carefully; however, the vulnerable blood vessel was probably damaged when the balloon was dilated and wedged into the artery, and pulmonary alveolar hemorrhage occurred due to the traumatic PA false aneurysm. Chest 3D CT images showed that the right main PA was pressed by the thoracic aortic aneurysm (Fig. 2). The chest 3D CT after surgery revealed that the PA Swan-Ganz catheter had shifted at the thoracic artery aneurysm level (Fig. 3). Therefore, there is a possibility that the tip of the PA Swan-Ganz catheter moved unexpectedly because of the existence of a thoracic aortic aneurysm, and the vulnerable blood vessel was damaged even though the PA Swan-Ganz catheter had been carefully 
operated.

Routine treatment for hemoptysis during general anesthesia includes $100 \%$ oxygen, changes in position to the bleeding lung side down, changing the tube to a double lumen, and PEEP $[3,4]$. Useful interventions for the management of endotracheal hemorrhage caused by PA injury include occlusion of the airway on the side of the bleeding by differential lung ventilation, bronchoscopic hemostasis, ventilation with PEEP, hemostasis by endovascular treatment, lobectomy, and direct repair of the PA [6-10]. Hemostasis by endovascular treatment or surgical treatment such as lobectomy is considered when conservative treatment is difficult or when there is intrathoracic hemorrhage $[1,3,6]$. In our patient, hemostasis was achieved within a short time by the application of high PEEP, and airway patency and ventilation could fortunately be maintained, probably because of the very limited extent of injury and the small size of the false aneurysm of the $\mathrm{PA}$ as demonstrated by imaging.

In general, patients with endotracheal hemorrhage due to iatrogenic trauma caused by a PA catheter are considered to remain at a high risk of rebleeding even after hemostasis has been achieved by conservative treatment $[1,3]$. Rebleeding is often characterized by rapid and massive bleeding, and it is more serious. Rebleeding reportedly occurs within 48 hours in most cases, although there are reports of rebleeding occurring a few weeks or even a few months after the initial bleeding $[1,3,6,8]$. If respiratory management is undertaken with a normal endotracheal tube, prevention of rebleeding is an especially important consideration during treatment. In the present case, sufficient sedation with propofol and analgesia with fentanyl was provided after hemostasis in the ICU with close monitoring of the patient.

Our patient had been diagnosed as having COPD complicated by PA hypertension. COPD can cause a pulmonary artery aneurysm $[2,11]$. Therefore, our patient might have had pulmonary alveolar fragility before the surgery. PA injury caused by the placement of a PA Swan-Ganz catheter might have resulted in endotracheal hemorrhage, transiently disrupting ventilation; however, successful hemostasis could be achieved by conservative treatment using high PEEP, and the patient recovered. PA catheters are still frequently used in the perioperative period, especially for patients with decreased cardiac function and during cardiovascular surgical procedures [12]. Our case report raises the possibility of unexpected alveolar hemorrhage in a patient who has a thoracic aortic aneurysm due to a traumatic PA false aneurysm caused by placement of a PA Swan-Ganz catheter. PA Swan-Ganz catheters need to be operated with much caution, especially in a patient who has a thoracic artery aneurysm.

\section{References}

1. McDaniel DD, Stone JG, Faltas AN, Khambatta HJ, Thys DM, Antunes AM, et al. Catheter-induced pulmonary artery hemorrhage. Diagnosis and management in cardiac operations. J Thorac Cardiovasc Surg 1981; 82: 1-4.

2. Shah KB, Rao TL, Laughlin S, El-Etr AA. A review of pulmonary artery catheterization in 6,245 patients. Anesthesiology 1984; 61: 271-5.

3. Urschel JD, Myerowitz PD. Catheter-induced pulmonary artery rupture in the setting of cardiopulmonary bypass. Ann Thorac Surg 1993; 56: 585-9.

4. Sirivella S, Gielchinsky I, Parsonnet V. Management of catheter-induced pulmonary artery perforation: a rare complication in cardiovascular operations. Ann Thorac Surg 2001; 72: 2056-9.

5. Ferretti GR, Thony F, Link KM, Durand M, Wollschläger K, Blin D, et al. False aneurysm of the pulmonary artery induced by a Swan-Ganz catheter: clinical presentation and radiologic management. AJR Am J Roentgenol 1996; 167: 941-5.

6. Carlson TA, Goldenberg IF, Murray PD, Tadavarthy SM, Walker M, Gobel FL. Catheter-induced delayed recurrent pulmonary artery hemorrhage. Intervention with therapeutic embolism of the pulmonary artery. JAMA 1989; 261: 1943-5.

7. Choong CK, Meyers BF. Lung mass after pulmonary artery catheterization: beware of the pulmonary artery false aneurysm. J Thorac Cardiovasc Surg 2005; 130: 899-900.

8. Feng WC, Singh AK, Drew T, Donat W. Swan-Ganz catheter-induced massive hemoptysis and pulmonary artery false aneurysm. Ann Thorac Surg 1990; 50: 644-6.

9. Olearchyk AS, Varada A. Perforation of the right pulmonary artery branch to the right middle lobe with a Swan-Ganz catheter during cardiopulmonary bypass, resulting in endobronchial hemorrhage. J Thorac Cardiovasc Surg 1991; 102: 807-8.

10. Urschel JD, Parrott JC. Repair of catheter-induced perforation of the pulmonary artery. Ann Thorac Surg 1991; 51: 1046.

11. Cherwek H, Amundson S. Images in clinical medicine. Pulmonary-artery aneurysm. N Engl J Med 2003; 348: e1.

12. Tempe DK, Gandhi A, Datt V, Gupta M, Tomar AS, Rajesh V, et al. Length of insertion for pulmonary artery catheters to locate different cardiac chambers in patients undergoing cardiac surgery. Br J Anaesth 2006; 9: 147-9. 